\title{
ИССЛЕДОВАНИЕ ПЕРЕРАСПРЕДЕЛЕНИЯ ТЕМПЕРАТУРЫ В ЧАСТИЦАХ ОБОЖЖЕННОГО ГИПСА
}

\section{INVESTIGATION OF TEMPERATURE REDISTRIBUTION IN THE CALCINED GYPSUM PARTICLES}

\author{
Представил д-р техн. наук, профессор А.А. Плугин
}

\begin{tabular}{llllll} 
Традиционная технология обжига & полугидрата & \multicolumn{2}{c}{ сульфата } & \multicolumn{2}{c}{ кальция } \\
гипса во вращающихся печах, как известно, & предусматривает остывание гипса после \\
приводит к значительному ослаблению & обжига в камере томления, чтобы избежать \\
структуры гипса в связи с резким & резкого перепада температуры частиц и \\
удалением воды в виде пара. Поэтому & еще большего разрушения их \\
технология & получения & т.н. & $\beta$-формы & кристаллической решетки [1]. & й \\
\hline
\end{tabular}


Для получения $\alpha$-формы гипсового вяжущего используют технологии, в которых предусмотрено наличие не только температуры, но и давления, чтобы обеспечить частичное удаление воды в жидком состоянии из сырья. В такой технологии реактор представляет собой динамическую систему, где нет резкого нагрева и резкого остывания, в связи с этим камера томления не предусмотрена [2].

Разработана оригинальная технология получения высококачественного гипса $\alpha$ формы с реализацией двух процессов теплообработки гипсового сырья.

На первом этапе тепловой обработки в реакторе, который имеет форму усеченного конуса, горячий воздушный поток вносит с широкого конца частицы измельченного гипса и выносит их из реактора через узкое отверстие. Вследствие сужения выходного отверстия реактора в его камере создается давление, необходимое для того, чтобы вода из гипса выделялась в жидком состоянии.

На этом этапе частицы обожженного гипса имеют смешанный химический состав и неравномерное распределение температуры по их глубине, что объясняется особенностью технологии обжига, т.к. время пребывания частиц в реакторе в условии высокой температуры и давления составляет секунды. К тому же температура теплоносителя всегда выше, чем температура обжига гипса для реализации процесса нагревания частиц сырья в результате теплопроводности.

Таким образом, образуется многофазная структура обожженного гипса, модель которого приведена на рис. 1.

Как показано на рис. 1, на поверхности частицы радиусом $\mathrm{R}$ образуется слой безводного гипса (растворимого сульфата кальция) толщиной от $\mathrm{R}$ до $\mathrm{R}_{2}$, затем слой полуводного гипса от $\mathrm{R}_{2}$ до $\mathrm{R}_{1}$, а центральная часть зерна представлена исходным двуводным гипсом радиусом $\mathrm{R}_{1}$.

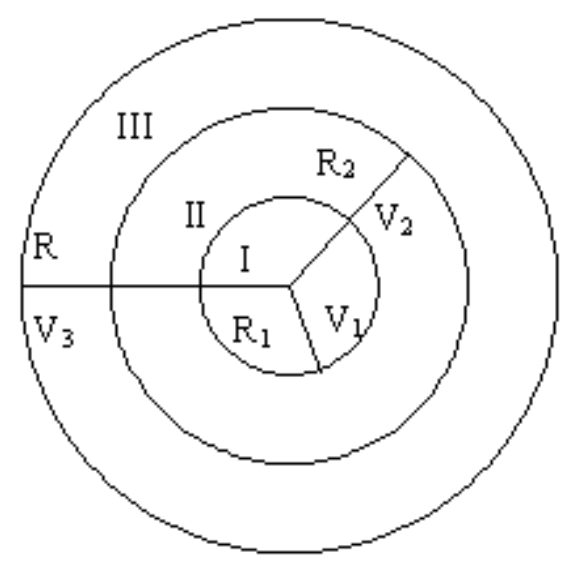

Рис. 1. Модель многофазной структуры частицы гипса после обжига в реакторе-конфузоре

Поэтому возникла необходимость введения в технологическую схему камеры томления, которая выполняет функцию второго реактора для выравнивания температуры в частицах и корректировки их химического состава.

Задачей тепловой обработки гипсового сырья является создание условий образования полуводного гипса по всему объему частицы. Для этого молекулы воды, которые выделяются при дегидратации в результате диффузии из центральной зоны, должны попасть в наружный слой, чтобы в нем произошла реакция образования полуводного гипса. Это возможно в случае перераспределения температур в частице, для чего в технологической схеме и предусмотрена камера томления. Режим обжига в реакторе-конфузоре должен обеспечивать согласованность размеров зон друг с другом для того, чтобы количество воды, выделяемой в центральной зоне, было необходимо и достаточно для образования полуводного гипса в наружном слое.

С этой целью были проведены исследования по изменению кристаллической структуры, плотности и линейных размеров частиц гипса в результате обжига при различных температурах. Установлено, что линейные 
размеры частиц гипса практически не изменяются, а плотность уменьшается пропорционально количеству удаленной физической и гидратной воды. Поэтому можно принять, что изменение плотности различных зон зависит от количества гидратной воды, т.е. пропорционально молярной массе растворимого ангидрита, полуводного и двуводного гипса.

Молярные массы молекул частиц во всех зонах и объемы зон приведены в таблице.

Таблица

Описание зон частицы гипса после обжига в реакторе-конфузоре

\begin{tabular}{|c|c|c|c|}
\hline $\begin{array}{c}\text { Наименование фазы } \\
\text { материала }\end{array}$ & $\begin{array}{c}\text { Химическая } \\
\text { формула }\end{array}$ & $\begin{array}{c}\text { Молярная масса, } \\
\text { г/моль }\end{array}$ & Объем фаз в частицах \\
\hline $\begin{array}{c}\text { I зона - двуводный } \\
\text { гипс }\end{array}$ & $\mathrm{CaSO}_{4} \cdot 2 \mathrm{H}_{2} \mathrm{O}$ & 172 & $\mathrm{~V}_{1}=4 / 3 \pi \mathrm{R}_{1}{ }^{3}$ \\
\hline $\begin{array}{c}\mathrm{II} \text { зона - полугидрат } \\
\text { сульфата кальция }\end{array}$ & $\mathrm{CaSO}_{4} \cdot 0,5 \mathrm{H}_{2} \mathrm{O}$ & 145 & $\mathrm{~V}_{2}=4 / 3 \pi\left(\mathrm{R}_{2}{ }^{3}-\mathrm{R}_{1}{ }^{3}\right)$ \\
\hline $\begin{array}{c}\text { III зона- } \\
\text { растворимый } \\
\text { ангидрит }\end{array}$ & $\mathrm{CaSO}_{4}$ & 136 & $\mathrm{~V}_{3}=4 / 3 \pi\left(\mathrm{R}^{3}-\mathrm{R}_{2}{ }^{3}\right)$ \\
\hline
\end{tabular}

Разница гидратной воды $\mathrm{H}_{2} \mathrm{O}$ в зонах I и II составляет 27 г/моль, а в зонах II и III 9 г/моль. Следовательно, для выравнивания содержания гидратной воды в I и III зонах необходимо следующее соотношение их объемов: $3 \mathrm{~V}_{1}=\mathrm{V}_{3}$, т. е.

$$
\pi \mathrm{R}_{1}^{3}=4 / 3 \pi \mathrm{R}^{3}-4 / 3 \pi \mathrm{R}_{2}^{3}
$$

Отсюда

$$
3 \mathrm{R}_{1}^{3}+\mathrm{R}_{2}^{3}=\mathrm{R}^{3}, \quad R_{2}=\sqrt[3]{R^{3}-3 R_{1}^{3}} .
$$

Примем размер частицы за $1, \mathrm{R}=1$, тогда

$$
R_{2}=\sqrt[3]{1-3 R_{1}^{3}}
$$

В интервале температур от $115^{\circ}$ до $210^{\circ} \mathrm{C}$ получаем полуводный гипс, при изменении температур от $210^{\circ}$ до $350^{\circ} \mathrm{C}$ $\alpha$-обезвоженный полугидрат и $\alpha$-растворимый ангидрит. Поэтому в зоне I температура должна быть ниже $115^{\circ} \mathrm{C}$, в зоне II $-115-210^{\circ} \mathrm{C}$, а в зоне III $-210-350^{\circ} \mathrm{C}$ [2].

В предельном случае, когда отсутствует зона II, т.е. $\mathrm{R}_{2}=\mathrm{R}_{1}$, получаем:

$$
\begin{gathered}
R_{2}=\sqrt[3]{1-3 R_{2}^{3}}, \quad 4 \mathrm{R}_{2}^{3}=1, \quad \mathrm{R}_{2}^{3}=1 / 4 \\
R_{2}=\frac{\sqrt[3]{2}}{2}
\end{gathered}
$$

На основании теоретических исследований и расчетов, а также путем экспериментального определения модификационного состава обожженного гипса в конусообразном реакторе была построена зависимость распределения температуры при различных соотношениях фаз в частицах материала. На рис. 2 приведен график распределения температуры внутри частиц при различных значениях $\mathrm{R}_{1}$ и $\mathrm{R}_{2}$, общий радиус частицы принимаем за единицу. 
Будівельні матеріали, конструкції та споруди

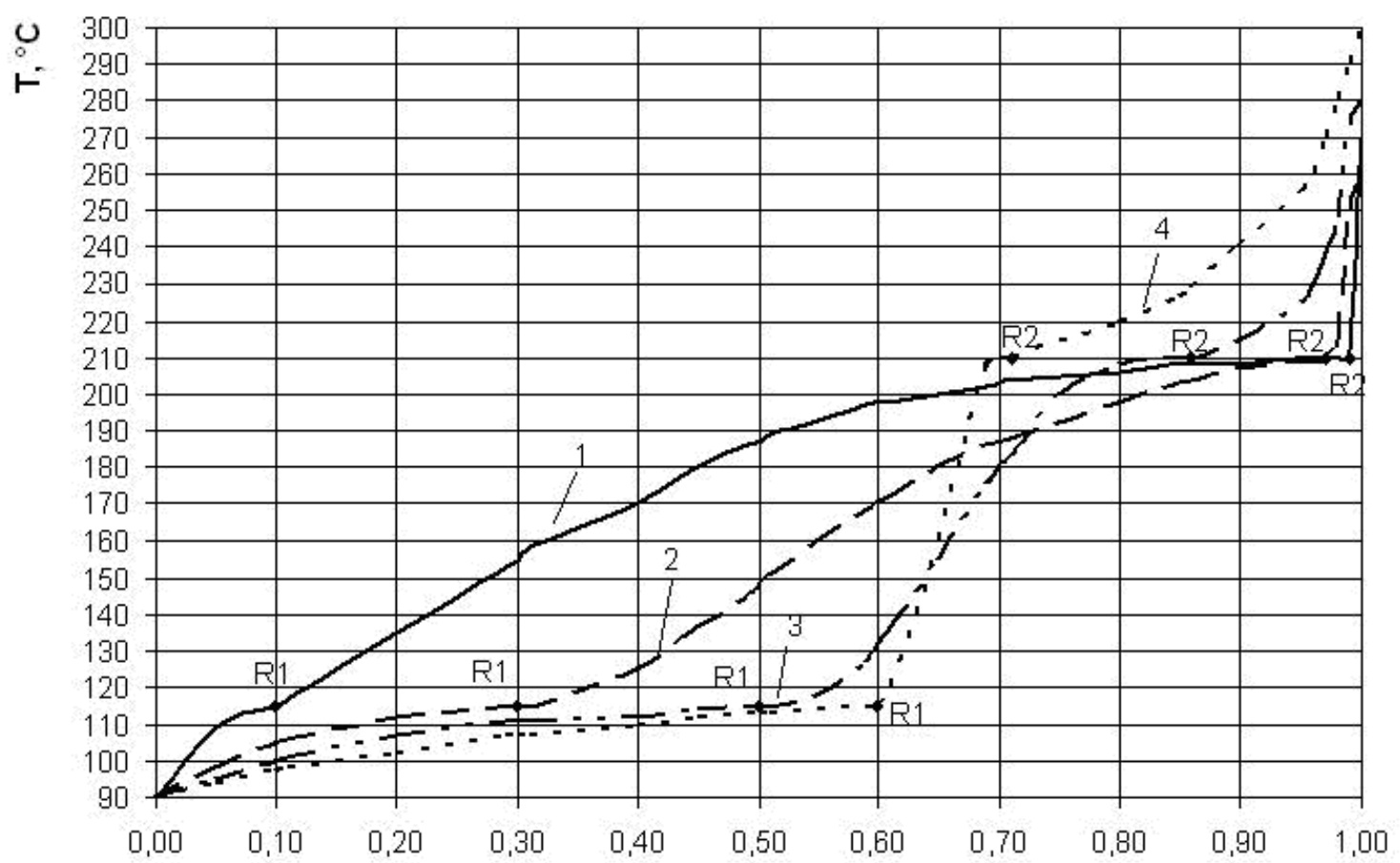

Радиус, R (в долях единицы)

Рис. 2. Зависимости распределения температуры при различных соотношениях фаз в частицах обожженного гипса:

$1-\mathrm{R}_{1}=0,1, \mathrm{R}_{2}=0,999 ; 2-\mathrm{R}_{1}=0,3, \mathrm{R}_{2}=0,97 ; 3-\mathrm{R}_{1}=0,5, \mathrm{R}_{2}=0,855 ; 4-\mathrm{R}_{1}=0,6, \mathrm{R}_{2}=0,71$

Частицы различного диаметра находятся в конусообразном реакторе разное время. Время нахождения частицы зависит от высоты реактора, скорости теплоносителя и ее скорости витания. Скорость движения частицы равна разности скорости потока теплоносителя и скорости витания. Поэтому распределение температуры в частице будет зависеть от ее размера и режима теплообработки (температуры теплоносителя и скорости его движения). Анализ рис. 2 показывает одинаковый качественный характер распределения температуры внутри частицы. Рост температуры в интервале до $110-115{ }^{\circ} \mathrm{C}$ наблюдается при изменении радиуса частицы от 0 до $\mathrm{R}_{1}$. В окрестности точки $\mathrm{R}_{1}$ наблюдается замедление роста температуры из-за фазовых превращений двуводного гипса в полуводный. Затем наблюдается равномерный рост температуры до точки $\mathrm{R}_{2}$, соответствующий температуре $200-210^{\circ} \mathrm{C}$ фазового превращения полуводного гипса в растворимый ангидрит. При точках от $\mathrm{R}_{2}$ и более наблюдается рост температур до 230$300^{\circ} \mathrm{C}$. Кривые 1 и 2 характерны для процесса нагревания мелких частиц, которые находятся непродолжительное время в конусообразном реакторе. В этом случае объем полуводного гипса составляет от $99,6-89,2 \% \quad\left(\mathrm{R}_{1}\right.$ изменяется от 0,1 радиуса частицы до 0,3 , a $\mathrm{R}_{2}$ соответственно от 0,999 до 0,972). Кривые 3 и 4 характерны для процесса нагревания крупных частиц, находящихся дольше на первой стадии термообработки, содержание полуводного гипса находится в пределах 13,6-50\%. При соблюдении соотношений между $\mathrm{R}_{1}$ и $\mathrm{R}_{2}$ будет обеспечено выравнивание химического состава обожженного гипса в камере томления и получен полуводный гипс. С этой целью были разработаны математические модели нагревания частицы в реакторе-конфузоре 
[3] и необходимого времени пребывания частиц в камере томления [4].

Математическая модель нагрева частицы гипса в реакторе была получена в результате решения уравнения теплопроводности путем использования метода Фурье.

Необходимо учитывать, что для каждой модификации гипса (ангидрита, полуводного и двуводного гипса) существуют различные значения удельной теплоемкости, плотности и коэффициента теплопроводности, причем вышеуказанные характеристики зависят еще и от температуры. Поэтому моделирование осуществлялось послойно, причем результаты расчета для і-того слоя использовались в постановке краевой задачи для следующего (i+1) слоя.

Модель необходимого времени пребывания частиц в камере томления с целью выравнивания температурного поля в частице гипса строилась как суперпозиция трех задач. Первая задача продолжающийся нагрев и дегидратация шаровидной зоны в центре частицы для двуводного гипса (с переходом его в полуводный) радиусом $R_{l}$. Эта задача решается аналогично решению задачи нагрева в реакторе, только при других краевых и начальных условиях.

Вторая задача - остывание наружного слоя безводного гипса (ангидрита) и насыщение его молекулами воды с образованием полуводного гипса.

Третья задача - остывание слоя полуводного гипса.

Вторая и третья задачи решаются на базе краевой задачи в сферических координатах об остывании шара, на поверхности которого поддерживается заданная температура.

Выводы. Разработана двухстадийная технология тепловой обработки гипса. Такой подход значительно сокращает время обжига сырого гипса и позволяет управлять процессом обжига, в зависимости от влажности и крупности частиц исходного сырья.

Предложена методика определения необходимого распределения температур в частицах гипса после обжига на первом этапе для условий их оптимальной теплообработки на втором этапе в камере томления. Рассчитано необходимое соотношение между объемами различных фаз в частице гипса для получения высококачественного полуводного гипса.

\section{Список литературы}

1. Кокшарев, В.Н. Тепловые установки [Текст] / В.Н. Кокшарев, А.А. Кучеренко. - К.: Вища школа, $1990 .-335$ с.

2. Ферронская, А.В. Гипсовые материалы и изделия (производство и применение) [Текст]: справочник / А.В. Ферронская. - М., 2004 - 485 с.

3. Кондращенко, Е.В. Перспективы энергосбережения при производстве гипсовых вяжущих [Текст] / Е.В. Кондращенко, А.А. Баранова // Науковий вісник будівництва. Харків: ХДТУБА, 2006. - Вип. 36. - С. 60-65.

4. Кондращенко, Е.В. Теоретические основы тепловой обработки гипсового вяжущего [Текст] / Е.В. Кондращенко, А.Н. Баранов, А.А. Баранова // Коммунальное хазяйство городов. - К.: Техника, 2007. - Вип. 76. - С. 132-138.

Ключевые слова: многофазная структура, двухстадийная технология, камера томления, распределения температуры. 


\section{Аннотации}

В статті наведена розроблена оригінальна технологія випалу гіпсового в'яжучого. Розроблено метод, який описує необхідне розподілення температури в частках гіпсу після випалу на першому етапі для умов їх теплообробки на другому етапі. Розраховано відношення між об’ємами різних зон у частці гіпсу для отримання $\alpha$-полугідрату сульфату кальцію.

В статье приведена разработанная оригинальная технология обжига гипсового вяжущего. Разработан метод, который описывает необходимое распределение температуры в частицах гипса после обжига на первом этапе для условий их тепловой обработки на втором этапе. Рассчитано отношение между объемами разных зон в частице гипса для получения $\alpha$ полугидрата сульфата кальция.

Designed original technology of the burning gypsum binding is brought in the paper. The designed method, witch is describing the temperature distribution in the particles of the gypsum after burning on the first stage for conditions their calcining on the second stage. Correlation between volumes of the different zones in particles of the gypsum for reception $\alpha$ - hemihydrate of sulphate calcium was calculate. 